\title{
Accumulation of health risk behaviours is associated with lower socioeconomic status and women's urban residence: a multilevel analysis in Japan Yoshiharu Fukuda*, Keiko Nakamura and Takehito Takano
}

\author{
Address: Health Promotion/International Health, Division of Public Health, Graduate School of Tokyo Medical and Dental University, 1-5-45 \\ Yushima, Bunkyo-ku, Tokyo 113-8519, Japan \\ Email: Yoshiharu Fukuda* - fukuda.hlth@tmd.ac.jp; Keiko Nakamura - nakamura.ith@tmd.ac.jp; Takehito Takano - secretary1.hlth@tmd.ac.jp \\ * Corresponding author
}

Published: 27 May 2005

BMC Public Health 2005, 5:53 doi:10.1 |86/147|-2458-5-53
Received: 19 October 2004

Accepted: 27 May 2005

This article is available from: http://www.biomedcentral.com/I47/-2458/5/53

(C) 2005 Fukuda et al; licensee BioMed Central Ltd.

This is an Open Access article distributed under the terms of the Creative Commons Attribution License (http://creativecommons.org/licenses/by/2.0), which permits unrestricted use, distribution, and reproduction in any medium, provided the original work is properly cited.

\begin{abstract}
Background: Little is known about the socioeconomic differences in health-related behaviours in Japan. The present study was performed to elucidate the effects of individual and regional socioeconomic factors on selected health risk behaviours among Japanese adults, with a particular focus on regional variations.
\end{abstract}

Methods: In a nationally representative sample aged 25 to 59 years old $(20,030$ men and 21,076 women), the relationships between six risk behaviours (i.e., current smoking, excessive alcohol consumption, poor dietary habits, physical inactivity, stress and non-attendance of health checkups), individual characteristics (i.e., age, marital status, occupation and household income) and regional $(N=60)$ indicators (per capita income and unemployment rate) were examined by multilevel analysis.

Results: Divorce, employment in women, lower occupational class and lower household income were generally associated with a higher likelihood of risk behaviour. The degrees of regional variation in risk behaviour and the influence of regional indicators were greater in women than in men: higher per capita income was significantly associated with current smoking, excessive alcohol consumption, stress and non-attendance of health check-ups in women.

Conclusion: Individual lower socioeconomic status was a substantial predictor of risk behaviour in both sexes, while a marked regional influence was observed only in women. The accumulation of risk behaviours in individuals with lower socioeconomic status and in women in areas with higher income, reflecting an urban context, may contribute to their higher mortality rates.

\section{Background}

Health inequality within the population is a major public health concern $[1,2]$. Individual socioeconomic status, as measured by educational level, occupational class and income, has been shown to be closely related to both mortality and morbidity in combination with race/ethnic- ity, access to health care services and a number of other factors $[3,4]$. Previous studies confirmed by that the relationship between socioeconomic factors and health status can be explained in part by differences in health-related behaviour according to socioeconomic status [5,6]. Generally, people with lower socioeconomic status have a 
higher likelihood of exposure to risk behaviours, such as smoking, excessive alcohol consumption, physical inactivity, poor diet and non-attendance of health check-ups, as well as psychological stress [7-13].

A number of recent studies, especially a series of multilevel analyses, have focused on the regional and contextual effects on health [14-16], and have demonstrated effects on mortality, morbidity and self-rated health [1720]. Regional socioeconomic conditions have been shown to influence health-related behaviour independently and interactively with individual socioeconomic status, and most previous studies indicated a higher likelihood of health risk behaviour in people living in socioeconomically disadvantaged areas [21-23].

Japan has the longest life expectancy and healthy life expectancy in the world [24], which has been shown to be due not only to improvements in the standard of living due to economic growth, but also to the relatively small degree of socioeconomic disparity within the population $[25,26]$. We are especially interested in the degree of socioeconomic inequalities in health and its relation to the status of the Japanese population as the healthiest worldwide, as well as the future implications.

There is only limited evidence of socioeconomic inequality in health in Japan. National data indicate a substantial gap in mortality among occupations: lower occupational classes, such as service workers and primary industry workers, show higher mortality rates than higher occupational classes, such as professionals and technical workers [27]. Previous studies demonstrated regional variations in mortality among municipalities, and areas with lower socioeconomic status were associated with higher rates of mortality [28]. However, recent figures have indicated clear gender differences in the relationships between area socioeconomic status and mortality: areas with higher income and educational level show lower mortality rates among men, but not among women [28].

Although a few studies in Japan have demonstrated a significant correlation between lower socioeconomic status and increased likelihood of risk behaviour at the individual level, the relationship was moderate as compared to that in other industrial nations $[29,30]$. At the regional level, there are substantial variations in the prefectural prevalence of smoking, alcohol drinking and other health risk behaviours [31]. Nevertheless, little is known about the independent impacts of individual and regional socioeconomic conditions on health risk behaviour, paying attention to integration of the influences at both levels in Japan.
The present study was performed to examine the relationships of individual and regional socioeconomic factors to health risk behaviour with regard to smoking, alcohol consumption, diet, exercise, psychological stress and attendance at health check-ups, by multilevel analysis of a nationally representative sample in Japan.

\section{Methods \\ Data source}

The 2001 Comprehensive Survey of the Living Conditions of People on Health and Welfare conducted by the Ministry of Health, Labour and Welfare [32] was used for analysis in the present study. All members of households within 5,240 area units, sampled randomly with stratification by prefecture in Japan, were interviewed. The survey included household and individual basic information regarding demographics, health, illness profiles, lifestyle and other items. The total number of households sampled for basic information was 247,195 , of which 30,386 were interviewed with regard to income and savings. The response rates were $87.4 \%$ for the basic information survey and $79.5 \%$ for the income survey. Microdata files from this survey were used with permission from the Ministry of Public Management, Home Affairs, Posts and Telecommunications; we analysed the data for 20,030 men and 21,076 women aged 25 to 59 years whose basic and income data were surveyed.

\section{Health risk behaviour}

The following six health risk behaviours were used in the analyses: current smoking, excessive alcohol consumption, poor dietary habits, physical inactivity, stress and non-attendance of health check-ups.

\section{Current smoking}

Smoking habits were surveyed based on the following four categories: (a) "I don't smoke"; (b) "I smoke every day"; (c) "I smoke on occasion but not every day"; and (d) "I have stopped smoking for more than one month". We categorised (b) and (c) as current smokers.

\section{Alcohol consumption}

Alcohol consumption per day was surveyed, and excessive alcohol consumption was defined as more than 2.0 "gou" per day (one "gou" is a measure of $180 \mathrm{ml}$ of Japanese sake, and contains almost $20 \mathrm{~g}$ of ethanol).

\section{Poor dietary habits}

Dietary habits were surveyed using the question, "What are your daily dietary practices?": have regular meals; have balanced meals; have bland (less salty) meals; and do not overeat. People who answered "no" to all these questions were defined as having poor dietary habits. 


\section{Physical inactivity}

The question was, "Do you exercise or play sports regularly?" People who answered "no" were defined as being physically inactive.

\section{Stress}

The question was, "Do you have any stress or worries in your daily life?" People who answered "yes" were defined as being stressed.

\section{Non-attendance of health check-ups}

The subjects' attendance of health check-ups in the past year was surveyed. Health check-ups included all types of general health check-up, such as periodical health examinations in the workplace, health examinations in communities and multiphasic examinations ("Ningen Dock"), but not health examinations only for cancer screening, maternal health check-ups, dental health examinations or clinical examinations at medical facilities.

\section{Individual socioeconomic variable}

We used age, marital status, occupation and income as individual socioeconomic variables.

Subjects' marital status was categorised as married, single, widowed or divorced. Occupation classification was based on the Vital Statistics in Japan [27]: professional and technical workers (professional); managers and officials (manager); clerical and related workers (clerk); sales workers (sales work); service workers (service work); protective service workers (protective service); agriculture, forestry and fishery workers (agriculture); workers in transport and communications (transport); craftsmen, mining, production process and construction workers and labourers (labour); housework; and others including workers not classifiable by occupation, the unemployed and students.

Annual household income before tax, including benefits and inheritance, was used as income information. To adjust for family size and composition, we applied the modified OECD equivalence scale of 1.0 for the first adult, 0.5 for the second and each subsequent person aged 14 and over, and 0.3 for each child under 14 [33]. The subjects were divided into quintiles according to equivalent income, and the income quintile was used as an independent variable.

\section{Regional socioeconomic variables}

Japan consists of 47 prefectures, and the prefecture was used the basic regional unit in the present study. For prefectures including a metropolitan city/cities, i.e., the Tokyo metropolitan area (23 special wards, "ku") and 12 cities designated by ordinance (Sapporo, Sendai, Chiba, Yokohama, Kawasaki, Nagoya, Kyoto, Osaka, Kobe, Hiro- shima, Kitakyushu and Fukuoka), the regional unit was divided into prefectures excluding metropolitan cities. Consequently, the individual data were linked with 47 prefectures and 13 metropolitan cities.

Per capita income and unemployment rate of prefectures and metropolitan cities were obtained from the database of census data and governmental surveys [34], and were used as regional socioeconomic variables.

\section{Statistical analysis}

Multilevel analysis was performed with data for 20,003 men and 21,076 women (level-1) nested within 60 prefectures/metropolitan cities (level-2). To estimate the average relationships between health risk behaviours and individual variables across all regions (individual fixed parameters), the variations between prefectures/metropolitan cities that could not be accounted for by individual factors (regional random variance), and the effects of regional variables on health risk behaviours (regional fixed parameter), a multilevel binomial non-linear logit link model using the iterative generalised least-squares (IGLS) was fitted [35].

Individual and regional fixed parameters were expressed by the adjusted odds ratio (OR) with 95\% confidence interval $(\mathrm{CI})$. The proportion of variance related to the region (intra-regional correlation:\%) was approximated as: regional variance/(regional variance $\left.+\pi^{2} / 3\right) \times 100$ $[36,37]$. Statistical analyses were performed using MLwiN version 1.10 [38].

\section{Results}

Table 1 shows the basic characteristics of the subjects included in the present study. The mean age was 42.9 years for both men and women. A large proportion of the subjects were classified as "married": $73.4 \%$ for men and $76.9 \%$ for women. The majority of women reported their occupation as "housework" (27.4\%). In the following analysis, "protective service" and "housework" for men, and "manager", "protective service," and "transport" for women were included in "others", because they each comprised only a very small proportion of the total. In multilevel analysis, the references were "profession" for men and "housework" for women. Per capita income and unemployment rate of 60 prefectures/metropolitan cities ranged from 865 to 2,042 (thousand yen) and 3.0 to 9.4 (\%), respectively.

The prevalence of difference health risk behaviours are shown in Table 2. Current smoking, excessive alcohol consumption and poor dietary habits were much more prevalent in men (57.3, 27.4 and $40.6 \%$, respectively) than in women (15.6, 5.8 and $27.4 \%$, respectively). Physical inactivity and stress were not markedly different 
Table I: Basic characteristics of study subjects and regions.

\begin{tabular}{|c|c|c|c|}
\hline & & Men & Women \\
\hline \multicolumn{4}{|c|}{ Individual variable ( 20030 men and 21076 women) } \\
\hline Age (mean, range: years) & & $42.9(25-59)$ & $42.9(25-59)$ \\
\hline \multirow[t]{4}{*}{ Marital status (N, \%) } & Married & $|470|(73.4)$ & $16208(76.9)$ \\
\hline & Single & $4635(23.1)$ & $3217(15.3)$ \\
\hline & Separated & $137(0.7)$ & $54 \mid(2.6)$ \\
\hline & Divorced & $557(2.8)$ & $1110(5.3)$ \\
\hline \multirow[t]{10}{*}{ Occupation a $(\mathrm{N}, \%)$} & Profession & $3747(18.7)$ & $2243(10.6)$ \\
\hline & Manager & $1736(8.7)$ & $310(1.5)$ \\
\hline & Clerk & $1776(8.9)$ & $3051(14.5)$ \\
\hline & Sales work & $1972(9.8)$ & $1785(8.5)$ \\
\hline & Service work & $1697(8.5)$ & $2242(10.6)$ \\
\hline & Agriculture & $680(3.4)$ & $535(2.5)$ \\
\hline & Transport & $1063(5.3)$ & $80(0.4)$ \\
\hline & Labour & $4752(23.7)$ & $2167(10.3)$ \\
\hline & Housework & $28(0.1)$ & $5765(27.4)$ \\
\hline & Others & $2579(12.9)$ & $2898(13.8)$ \\
\hline \multirow[t]{5}{*}{ Income quintile (median: thousand yen) } & 5th (highest) & \multicolumn{2}{|c|}{6035} \\
\hline & 4th & \multicolumn{2}{|c|}{4000} \\
\hline & $3 r d$ & \multicolumn{2}{|c|}{2989} \\
\hline & 2nd & \multicolumn{2}{|c|}{2200} \\
\hline & Ist (lowest) & \multicolumn{2}{|c|}{1250} \\
\hline \multicolumn{4}{|c|}{ Regional variable (60 prefectures and metropolitan cities) } \\
\hline \multicolumn{2}{|c|}{ Per capita income (mean, range: thousand yen) } & \multicolumn{2}{|c|}{1423.4 (865-2042) } \\
\hline \multicolumn{2}{|c|}{ Unemployment rate (mean, range: \%) } & \multicolumn{2}{|c|}{$4.68(3.0-9.4)$} \\
\hline
\end{tabular}

a Profession $=$ professional and technical workers; clerk = clerical and related workers; agriculture $=$ agriculture, foresty and fishery workers; labour $=$ craftmen, mining, production process and construction workers, and labourers.

Table 2: Prevalence of health risk behaviour in Japanese adults

\begin{tabular}{|c|c|c|c|c|}
\hline \multirow[t]{2}{*}{ Health risk behavior } & \multicolumn{2}{|c|}{ Men } & \multicolumn{2}{|c|}{ Women } \\
\hline & $\mathrm{N}$ & (\%) & $\mathrm{N}$ & (\%) \\
\hline Current smoking & 10784 & $(57.3)$ & 3099 & $(15.6)$ \\
\hline Excess alcohol consumption & 5177 & $(27.4)$ & 1155 & $(5.8)$ \\
\hline Physical inactivity & 13989 & (7I.2) & 14926 & (72.0) \\
\hline Poor dietary habits & 7974 & $(40.6)$ & 5671 & $(27.4)$ \\
\hline Stress & 9639 & (51.9) & $1215 \mid$ & $(61.3)$ \\
\hline Non-attendance of health check-ups & 5243 & $(27.5)$ & 8532 & $(42.3)$ \\
\hline
\end{tabular}

between men and women, but women showed a higher prevalence of non-attendance of health check-ups than men ( $42.3 \%$ vs. $27.5 \%$, respectively).

Table 3 shows the results of multilevel analysis of the relationships between health risk behaviours and individual and regional socioeconomic variables for men. Compared to married subjects, those who were divorced showed significantly higher OR for current smoking, poor dietary habits and non-attendance of health check-ups. Subjects in lower occupational classes, such as "service work", "transport," and "labour", showed significantly higher OR for risk behaviours as compared to those classified as "professional". There was a significant gradient of increased OR according to income, except with regard to excessive alcohol consumption and stress. 
Table 3: Results of multilevel analysis for health risk behaviour in Japanese men: odds ratio (OR) and $95 \%$ confidence interval (95\%Cl) of individual and regional variables.

\begin{tabular}{|c|c|c|c|c|c|c|c|c|c|c|c|c|}
\hline \multirow{2}{*}{$\begin{array}{l}\text { Variable } \\
\text { Individual }\end{array}$} & \multicolumn{2}{|c|}{$\begin{array}{l}\text { Current smoking }(\mathrm{N}= \\
19816)\end{array}$} & \multicolumn{2}{|c|}{$\begin{array}{c}\text { Excess alcohol } \\
\text { consumption }(\mathrm{N}= \\
\text { I8922) }\end{array}$} & \multicolumn{2}{|c|}{$\begin{array}{c}\text { Physical inactivity }(\mathrm{N}= \\
20728)\end{array}$} & \multicolumn{2}{|c|}{$\begin{array}{l}\text { Poor dietary habits }(\mathrm{N}= \\
20728)\end{array}$} & \multicolumn{2}{|c|}{ Stress $(N=19817)$} & \multicolumn{2}{|c|}{$\begin{array}{l}\text { Non-attendance of } \\
\text { health check-up }(\mathrm{N}= \\
20148)\end{array}$} \\
\hline & OR & $(95 \% \mathrm{Cl})$ & OR & $(95 \% \mathrm{Cl})$ & OR & $(95 \% \mathrm{Cl})$ & OR & $(95 \% \mathrm{Cl})$ & OR & $(95 \% \mathrm{Cl})$ & OR & $(95 \% \mathrm{Cl})$ \\
\hline \multicolumn{13}{|l|}{ Individual } \\
\hline Age ( 10 years) & 0.81 & $(0.78,0.84) * * *$ & 1.17 & $(1.12,1.21)^{* * *}$ & 0.93 & $(0.90,0.97) *$ & 0.71 & $(0.69,0.74)$ **** & 1.01 & $(0.98,1.04)$ & 0.88 & $(0.84,0.91)$ **** \\
\hline \multicolumn{13}{|c|}{ we (1) } \\
\hline Married & 1.00 & & 1.00 & & 1.00 & & 1.00 & & 1.00 & & 1.00 & \\
\hline Single & 0.72 & $(0.66,0.78)$ ***k & 0.62 & $(0.56,0.68) * * *$ & 0.98 & $(0.90,1.07)$ & 1.04 & $(0.96,1.13)$ & 0.82 & $(0.75,0.88) * * *$ & 1.73 & $(1.58,1.89) * * *$ \\
\hline Widow & 1.35 & $(0.93,1.95)$ & 0.83 & $(0.55,1.25)$ & 1.08 & $(0.72,1.62)$ & 1.28 & $(0.87,1.87)$ & 0.97 & $(0.67, I .4 I)$ & 1.11 & $(0.71,1.74)$ \\
\hline Divorced & 1.89 & $(1.55,2.31)$ *** & 1.10 & $(0.91,1.33)$ & 1.14 & $(0.93,1.40)$ & 1.28 & $(1.06,1.53) *$ & 1.06 & $(0.88,1.27)$ & 1.75 & $(1.43,2.12)$ *** \\
\hline \multicolumn{13}{|l|}{ Occupation a } \\
\hline Profession & 1.00 & & 1.00 & & 1.00 & & 1.00 & & 1.00 & & 1.00 & \\
\hline Manager & 1.14 & $(1.01,1.28) *$ & 1.07 & $(0.93,1.22)$ & 0.94 & $(0.83,1.07)$ & 0.92 & $(0.81,1.05)$ & 1.03 & $(0.92,1.16)$ & 0.78 & $(0.67,0.92)$ **** \\
\hline Clerk & 0.94 & $(0.84,1.06)$ & 0.97 & $(0.85,1.11)$ & 1.06 & $(0.93,1.20)$ & 0.96 & $(0.85,1.09)$ & 0.99 & $(0.88,1.11)$ & 0.59 & $(0.50,0.69)$ *** \\
\hline Sales work & 1.31 & $(1.17,1.47)$ ***⿰冫⿰亅⿱丿丶丶 & 1.18 & $(1.04,1.34) *$ & 1.11 & $(0.98,1.25)$ & 1.06 & $(0.94,1.19)$ & 1.01 & $(0.90,1.13)$ & 1.68 & $(1.47,1.91)$ **** \\
\hline Service work & 1.26 & $(1.12,1.42)$ *** & 1.13 & $(0.98,1.29)$ & 1.20 & $(1.05,1.37) *$ & 1.19 & $(1.06,1.35) * *$ & 1.07 & $(0.95,1.21)$ & 1.34 & $(1.17,1.54) * * *$ \\
\hline Agriculture & 1.16 & $(0.97,1.39)$ & 1.20 & $(0.99,1.46)$ & 1.03 & $(0.85,1.25)$ & 0.93 & $(0.77,1.11)$ & 0.73 & $(0.61,0.87) * * *$ & 1.84 & $(1.52,2.24) * * *$ \\
\hline Trasnport & 1.61 & $(1.39,1.87) * * *$ & 1.29 & $(1.10,1.5 \mathrm{I})$ ** & 1.19 & $(1.01,1.39) *$ & 1.35 & $(1.16,1.56)$ *** & 0.92 & $(0.80,1.06)$ & 1.08 & $(0.91,1.28)$ \\
\hline Labour & 1.49 & $(1.36,1.63)$ *** & 1.26 & $(1.14,1.39)^{* * *}$ & 1.13 & $(1.03,1.25) *$ & 1.12 & $(1.02,1.23) *$ & 0.89 & $(0.81,0.98)^{*}$ & 1.10 & $(0.99,1.22)$ \\
\hline Others & 1.08 & $(0.97,1.20)$ & 0.91 & $(0.80,1.03)$ & 0.90 & $(0.80,1.01)$ & 1.00 & $(0.89,1.1 \mathrm{I})$ & 1.03 & $(0.92,1.15)$ & 1.33 & $(1.17,1.50) * * *$ \\
\hline \multicolumn{13}{|l|}{ Income quintile } \\
\hline 5th (highest) & 1.00 & & 1.00 & & 1.00 & & 1.00 & & 1.00 & & 1.00 & \\
\hline 4 th & 1.11 & $(1.01,1.21) *$ & 0.96 & $(0.87,1.06)$ & 1.17 & $(1.06,1.29)$ **** & 1.08 & $(0.98,1.19)$ & 1.10 & $(1.00,1.20) *$ & 1.10 & $(0.98,1.24)$ \\
\hline $3 r d$ & 1.12 & $(1.02,1.23) *$ & 0.99 & $(0.89,1.10)$ & 1.31 & $(1.19,1.45)$ **** & 1.16 & $(1.06,1.28) * *$ & 1.07 & $(0.97,1.17)$ & 1.34 & $(1.19,1.50) * * *$ \\
\hline 2nd & 1.30 & $(1.18,1.43)$ ***⿰冫⿰亅⿱丿丶丶 & 1.03 & $(0.92,1.14)$ & 1.43 & $(1.29,1.58) * * * k$ & 1.26 & $(1.14,1.39) * * *$ & 1.09 & $(0.99,1.20)$ & 1.99 & $(1.77,2.23) * * *$ \\
\hline Ist (lowest) & 1.29 & $(1.17,1.43) * * *$ & 0.99 & $(0.89,1.10)$ & 1.42 & $(1.28,1.58)$ ***⿰冫⿰亅⿱丿丶丶 & 1.28 & $(1.16,1.42) * * *$ & 1.15 & $(1.05,1.27) * *$ & 3.14 & $(2.80,3.52) * * *$ \\
\hline \multicolumn{13}{|l|}{ Region } \\
\hline $\begin{array}{l}\text { Per capita income } \\
\text { (million yen) }\end{array}$ & 0.89 & $(0.71,1.11)$ & 1.03 & $(0.82,1.29)$ & 1.05 & $(0.92,1.20)$ & 1.09 & $(0.94,1.26)$ & 1.44 & $(1.24,1.67)^{* * * *}$ & 1.42 & $(1.15,1.76) * *$ \\
\hline Unemployment (\%) & 1.06 & $(1.01,1.12) *$ & 1.07 & $(1.01,1.13) *$ & 0.99 & $(0.96,1.02)$ & 1.02 & $(0.99,1.06)$ & 1.01 & $(0.98,1.05)$ & 1.11 & $(1.05,1.16) * *$ \\
\hline $\begin{array}{l}\text { Regional random } \\
\text { variance (SE) }{ }^{b}\end{array}$ & 0.029 & $(0.008) * * *$ & 0.028 & $(0.008) * * *$ & 0.000 & $(0.000)$ & 0.004 & $(0.003)$ & 0.005 & $(0.003)$ & 0.029 & $(0.009) * *$ \\
\hline-2 log likelihood & & 26317.0 & & 22089.1 & & 23313.1 & & 25487.2 & & 26207.1 & & 19463.1 \\
\hline $\begin{array}{l}\text { Intra-regional } \\
\text { correlation (\%) }\end{array}$ & & 8.0 & & 7.7 & & 0.0 & & 1.1 & & 1.6 & & 8.0 \\
\hline
\end{tabular}

$* p<0.05, * * p<0.01, * * * p<0.001$

a Profession $=$ professional and technical workers; manager $=$ managers and officials; clerk = clerical and related workers; agriculture = agriculture, forestiry and fishery workers; transport = workers in transport and communications; labour = craftmen, mining, production process, and construction workers and labourers.

b Variance at the regional level in a logit model

With regard to regional indicators, significant correlations were found between per capita income and stress and non-attendance of health check-ups, and between unemployment rate and current smoking, excessive alcohol consumption and non-attendance of health check-ups. Significant regional variance was observed for current smoking, excessive alcohol consumption and non-attendance of health check-ups.

Table 4 shows the results of multilevel analysis for women. Being divorced showed a significantly higher OR for current smoking, excessive alcohol consumption, poor dietary habits and stress. Non-attendance of health checkups showed significantly lower OR for all types of employment as compared to "housework", while no significant differences were observed between OR for other health risk behaviours and any type of employment except for the relationship between current smoking and "agriculture". Higher income was associated with reduced likelihood of all risk behaviours. The strongest relationships were found for current smoking and non-attendance of health check-ups, which showed approximately two-fold greater odds in the lowest quintile as compared to the highest quintile.

Per capita income and unemployment rate showed significant positive associations with current smoking, excessive alcohol consumption, stress and non-attendance of health check-ups. With the exception of stress, all risk behaviours showed significant regional variance. All risk 
Table 4: Results of multilevel analysis for health risk behaviour in Japanese women: odds ratio (OR) and $95 \%$ confidence interval $(95 \% \mathrm{Cl})$ of individual and regional variables.

\begin{tabular}{|c|c|c|c|c|c|c|c|c|c|c|c|c|}
\hline \multirow[t]{2}{*}{ Variable } & \multicolumn{2}{|c|}{$\begin{array}{l}\text { Current smoking } \\
(N=19816)\end{array}$} & \multicolumn{2}{|c|}{$\begin{array}{l}\text { Excess alcohol } \\
\text { consumption } \\
(N=18922)\end{array}$} & \multicolumn{2}{|c|}{$\begin{array}{l}\text { Physical inactivity } \\
(N=20728)\end{array}$} & \multicolumn{2}{|c|}{$\begin{array}{l}\text { Poor dietary habits } \\
\quad(N=20728)\end{array}$} & \multicolumn{2}{|c|}{ Stress $(N=19817)$} & \multicolumn{2}{|c|}{$\begin{array}{c}\text { Non-attendance of } \\
\text { check-up } \\
(N=20148)\end{array}$} \\
\hline & OR & $(95 \% \mathrm{Cl})$ & OR & $(95 \% \mathrm{Cl})$ & OR & $(95 \% \mathrm{Cl})$ & OR & $(95 \% \mathrm{Cl})$ & OR & $(95 \% \mathrm{Cl})$ & OR & $(95 \% \mathrm{Cl})$ \\
\hline \multicolumn{13}{|l|}{ Individual } \\
\hline Age (10 years) & 0.76 & $(0.73,0.79) * * * *$ & 0.93 & $(0.87,1.00)$ & 0.70 & $(0.65,0.75)^{* * * *}$ & 0.70 & $(0.68,0.73) * * * *$ & 0.93 & $(0.90,0.96)$ ** & 0.65 & $(0.63,0.68)$ **** \\
\hline \multicolumn{13}{|c|}{ 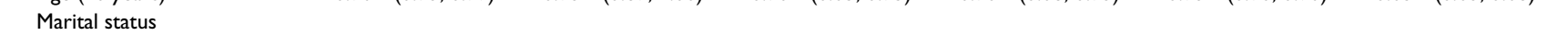 } \\
\hline Married & 1.00 & & 1.00 & & 1.00 & & 1.00 & & 1.00 & & 1.00 & \\
\hline Single & 1.00 & $(0.89,1.14)$ & 1.00 & $(0.82,1.21)$ & 0.73 & $(0.65,0.81)$ ** & 1.12 & $(1.01,1.24) *$ & 0.73 & $(0.66,0.80)$ **** & 0.63 & $(0.57,0.70)$ *** \\
\hline Widow & 1.07 & $(0.82,1.40)$ & 0.76 & $(0.49,1.19)$ & 1.11 & $(0.91,1.35)$ & 1.09 & $(0.87,1.36)$ & 0.92 & $(0.76,1.11)$ & 0.82 & $(0.67,1.02)$ \\
\hline Divorced & 2.67 & $(2.30,3.09) * * *$ & 1.68 & $(1.33,2.11)$ ***⿰冫⿰亅⿱丿丶丶 & 1.09 & $(0.93,1.27)$ & 1.23 & $(1.06,1.42) * *$ & 1.16 & $(1.01,1.34) *$ & 0.88 & $(0.76,1.02)$ \\
\hline \multicolumn{13}{|l|}{ Occupation a } \\
\hline Housework & 1.00 & & 1.00 & & 1.00 & & 1.00 & & 1.00 & & 1.00 & \\
\hline Profession & 1.08 & $(0.92,1.25)$ & 1.34 & $(1.06,1.70) *$ & 1.01 & $(0.90,1.14)$ & 1.03 & $(0.91,1.17)$ & 1.32 & $(1.18,1.47) * * * *$ & 0.26 & $(0.24,0.30)$ **** \\
\hline Clerk & 0.97 & $(0.84,1.12)$ & 1.46 & $(1.19,1.80) * * *$ & 1.15 & $(1.03,1.28) * *$ & 1.06 & $(0.95,1.19)$ & 1.20 & $(1.09,1.33) * * *$ & 0.28 & $(0.25,0.31)$ **⿰冫夬 \\
\hline Sales work & 1.57 & $(1.35,1.82) * * * *$ & 1.79 & $(1.42,2.25)$ *⿰冫⿰㇇⿰亅⿱丿丶丶 & 1.11 & $(0.98,1.25)$ & 1.43 & $(1.26,1.62) * * *$ & 1.19 & $(1.06,1.34) * *$ & 0.48 & $(0.43,0.54)$ *** \\
\hline Service work & 1.58 & $(1.37,1.81)^{* * * *}$ & 1.91 & $(1.55,2.36) * * *$ & 1.10 & $(0.98,1.23)$ & 1.37 & $(1.22,1.54) * * *$ & 1.14 & $(1.03,1.28) *$ & 0.42 & 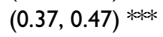 \\
\hline Agriculture & 0.70 & $(0.52,0.96) *$ & 1.21 & $(0.79,1.86)$ & 0.99 & $(0.81,1.22)$ & 1.06 & $(0.85,1.32)$ & 0.84 & $(0.70,1.02)$ & 0.56 & 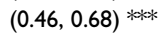 \\
\hline Labour & 1.10 & $(0.94,1.28)$ & 1.07 & $(0.83,1.38)$ & 1.35 & $(1.20,1.52)$ **** & 1.38 & $(1.23,1.56) * * *$ & 1.06 & $(0.95,1.18)$ & 0.36 & $(0.32,0.40)$ *** \\
\hline Others & 1.30 & $(1.13,1.48)$ *** & 1.34 & $(1.08,1.66) * * *$ & 1.03 & $(0.93,1.15)$ & 1.22 & $(1.09,1.36) * *$ & 1.06 & $(0.96,1.17)$ & 0.53 & $(0.48,0.59)$ *** \\
\hline \multicolumn{13}{|l|}{ Income quintile } \\
\hline 5th (highest) & 1.00 & & 1.00 & & 1.00 & & 1.00 & & 1.00 & & 1.00 & \\
\hline 4th & 1.12 & $(0.97,1.29)$ & 0.96 & $(0.78,1.17)$ & 1.06 & $(0.96,1.17)$ & 1.18 & $(1.06,1.32) * *$ & 1.06 & $(0.97,1.17)$ & 1.21 & $(1.09,1.34)$ *** \\
\hline $3 r d$ & 1.34 & $(1.16,1.54) * *$ & 1.04 & $(0.85,1.27)$ & 1.11 & $(1.00,1.22) *$ & 1.24 & $(1.11,1.39) * * *$ & I.II & $(1.01,1.22) *$ & 1.42 & $(1.29,1.58)$ **⿰冫夬 \\
\hline 2nd & 1.66 & $(1.44,1.90) * * * *$ & 1.06 & $(0.86,1.29)$ & 1.21 & $(1.09,1.34) * * * *$ & 1.32 & $(1.19,1.48) * * * *$ & 1.14 & $(1.04,1.26) * *$ & 1.75 & $(1.58,1.93)$ *** \\
\hline Ist (lowest) & 2.03 & $(1.76,2.33) * * k *$ & 1.28 & $(1.04,1.56) *$ & 1.24 & $(1.12,1.38) * * *$ & 1.64 & $(1.47,1.83)^{* * * *}$ & 1.26 & $(1.14,1.39) * * *$ & 2.23 & $(2.01,2.47)$ *** \\
\hline \multicolumn{13}{|l|}{ Region } \\
\hline Per capita income (million yen) & 1.93 & $(1.64,2.28) * *$ & 1.49 & $(1.05,2.10) *$ & 0.76 & $(0.64,0.90) * *$ & 1.12 & $(0.90,1.40)$ & 1.43 & $(1.23,1.67) * * * *$ & 1.75 & $(1.13,2.27)$ **** \\
\hline Unemployment (\%) & 1.08 & $(0.99,1.18)$ & 1.10 & $(1.03,1.19) *$ & 0.95 & $(0.92,0.99)$ ** & 1.03 & $(0.98,1.08)$ & 1.00 & $(0.97,1.04)$ & 1.09 & $(1.03,1.15)$ ** \\
\hline Regional random variance (SE) b & 0.118 & $(0.026) * * *$ & 0.043 & $(0.019) *$ & 0.009 & $(0.004) *$ & 0.032 & 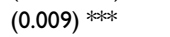 & 0.007 & $(0.004)$ & 0.045 & $(0.011) * * *$ \\
\hline-2 log likelihood & & 13564.2 & & -2382.9 & & 23140.5 & & 23489.1 & & 26988.4 & & 23946.7 \\
\hline Intra-regional correlation (\%) & & 26.1 & & 11.4 & & 2.6 & & 8.8 & & 2.1 & & 11.8 \\
\hline
\end{tabular}

$* \mathrm{p}<0.05, * * \mathrm{p}<0.01, * * * \mathrm{p}<0.001$

a Profession = professional and technical workers; clerk = clerical and related workers; agriculture = agriculture, foresty and fishery workers; labour = craftmen, mining, production process and construction workers, and labourers.

b Variance at the regional level in a logit model

behaviours showed higher intra-regional correlations as compared to men: in particular, $26.1 \%$ for current smoking, $11.8 \%$ for non-attendance of health check-ups and $11.4 \%$ for excessive alcohol consumption.

\section{Discussion}

The results of the present study indicated a substantial relationship between health risk behaviour and lower socioeconomic status at the level of the individual in Japanese men and women. The regional variance and the influence of regional socioeconomic indicators on risk behaviour were marked in women, but small in men.

Among men, those in the lower occupational classes showed a higher likelihood of risk behaviours, except for stress, as compared to "professionals". Especially, "service work," "transport" and "labour" showed significantly higher likelihood of current smoking, excessive alcohol consumption, physical inactivity and poor dietary habits.
These observations suggest a plausible explanation for the higher mortality rates among these occupational classes noted in the national data [27].

Individual income was significantly related to risk behaviour of smoking, exercise, diet and health check-ups in both men and women, and lower income increased the likelihood of these behaviours. In men, a clear gradient of OR was found only for non-attendance of health checkups and the gradient of OR for risk behaviours was not clearer than that of women. The model without occupation showed a clear gradient of OR in men [39] indicating a substantial degree of income-related inequality in health behaviour and its interaction with occupational class in Japanese men.

For women, no occupation showed a significantly lower OR as compared to "housework", with the exception of current smoking for "agriculture" and non-attendance of 
health check-ups for all occupational categories. This suggests that employment is associated with risk behaviour in women. Previous studies demonstrated that women's participation in society was related to a higher prevalence of smoking in accordance with the reduced intolerance toward this habit in women $[40,41]$. In addition, the tendency for higher OR of current smoking, excessive alcohol consumption and poor dietary habits in "sales workers" and "service workers" among the occupational categories implies the accumulation of risk behaviours in Japanese women in lower occupational classes.

It is interesting that excessive alcohol consumption did not show an income-related gradient in either men or women: the second highest quintile in men showed a significantly lower OR and the lowest quintile in women showed a significantly higher OR as compared to the highest quintile. For women, the difference in excessive alcohol consumption by occupation was greater than those in the other health risk behaviours. A previous study confirmed that participation in the workforce increases women's drinking habit in Japan [42].

The relationship between individual socioeconomic status and non-attendance of health check-ups showed a different pattern from other behaviours. Women in the "housework" category and men in the "agriculture" category were less likely to attend health check-ups. Health check-ups in people of working age are strongly dependent on the workplace [43]. Employees, particularly in large companies, have greater benefits of not only occupational health services but also preventive health services $[44,45]$. The steepest gradient of OR for non-attendance of health check-ups among all health risk behaviours suggests substantial inequality in receiving preventive health services according to socioeconomic status in the Japanese population.

There was a clear gender difference in the influence of regional socioeconomic indicators on health risk behaviour. All risk behaviours showed higher intra-regional correlations in women than in men, and marked differences were found for current smoking and excessive alcohol consumption. Area socioeconomic conditions have been shown to influence health-related behaviour, and in general those living in socioeconomically disadvantaged areas have a higher likelihood of health risk behaviour $[7,13,23,46]$. However, similarly to previous studies in France showing correlations between higher gross domestic product per capita in residential areas and both smoking and alcohol consumption $[47,48]$, the results of the present study indicated that women living in areas with higher per capita income had higher likelihood of current smoking, excessive alcohol consumption, stress and non- attendance of health check-ups. This may be explained by the following two points.

First, the regional differences in socioeconomic conditions in Japan are relatively small, and thus, regional disadvantage and deprivation would have little influence on individual health-related behaviour in the Japanese population. The data indicated that the degree of income inequality in Japan is smaller than in other industrial countries $[49,50]$, and the regional inequality in per capita income has decreased over the past several decades [51]. As a previous study demonstrated that national financial adjustment policy contributed to a reduction of regional disparity in health levels [52], a national minimum across the country was achieved by egalitarian social policies in Japan.

A second explanation is related to the linkage between per capita income and urban-rural differences. In Japan, indicators reflecting urbanisation, such as population size and population density, are strongly correlated with higher income, and therefore income-related indicators represent not only socioeconomic conditions but also aspects of urban-rural differences - higher per capita income indicates an urban context $[28,53,54]$. Therefore, the results of the present study imply a relationship between a higher likelihood of health risk behaviour and urbanisation. Urbanisation accompanied by social participation of women is likely to increase the likelihood of smoking and alcohol drinking in Japan [40-42].

One notable feature of the geographical variation in Japan is the deteriorating relative health levels of urban populations, especially for women. Osaka Prefecture, which is the second largest metropolis after the Tokyo Metropolitan Area, had the second shortest life expectancy for women among the 47 prefectures in Japan [55]. In addition, life expectancy in the Tokyo Metropolis, which had the longest life expectancy before 1965, ranked 15th for men and 37th for women in 2000 [55]. Urban areas showed higher mortality rates from cancer and ischemic heart disease than rural areas [56], and individual healthrelated behaviour contributes strongly to these diseases $[23,57,58]$.

For men, higher mortality rates are found in areas with lower income- and education-related indicators [28]. As shown in the present study, regional socioeconomic indicators had little influence on health risk behaviour in men taking individual socioeconomic indicators into consideration. As mentioned above, a previous study indicated a gender-related difference in the relationship between mortality and area socioeconomic status: higher mortality rates in areas with lower per capita income were seen only in men [28]. The higher likelihood of health risk behav- 
iour in men on the lower socioeconomic scale suggests one plausible explanation for the higher mortality in areas with lower per capita income, where lower-income individuals are more likely to live. In contrast, the relationship between health risk behaviour and higher per capita income can explain the marked deterioration of health level in women in urban areas with higher per capita income.

Finally, it is necessary to discuss the limitations of this study, as well as its strengths. The present study was performed in a large nationally representative sample with stratified random sampling, although potential differences in response rates based on socioeconomic status and region may have caused selection bias $[59,60]$. The questionnaire regarding health risk behaviour was comprehensive, although it was self-reported and a few behaviours (e.g., poor dietary habits and physical inactivity) are quite subjective. The items of dietary habits were based on the national guidelines for a healthy diet [61], and they (or the index formulated using these items) have been shown to be related to some aspects of physical health status $[62,63]$. Nevertheless, the validity and reliability of these questions have not been examined in detail, and those of single-item questions about physical activity were verified but only moderately so $[64,65]$. These issues probably induced misclassification bias $[59,60]$.

In this study, we effectively applied multilevel analysis to elucidate the influence of socioeconomic factors of two levels and to demonstrate regional variances. However, our models did not consider random effects of the variables or interactions between the variables. Supplemental analysis using random slope models for household income did not show statistically significant regional variance in the effects of household income on any health risk behaviour in either men or women (data not shown).

Other limitations are related to the measurements of socioeconomic status. In the present study, household income was used as the main measure of individual socioeconomic status, which was estimated from the details of income-related information and adjusted for family size and composition. Educational attainment is also commonly used as another major measure of socioeconomic status $[66,67]$. As the survey used in the present study did not include educational information, no educationrelated variable could be introduced into the analyses. Previous studies have shown that differences in healthrelated behaviour among groups stratified according to educational attainment in Japan are substantial $[29,30,68]$. Further studies are required to clarify the independent and interactive influences of different socioeconomic measures on health risk behaviour.

\section{Conclusion}

The results of the present study demonstrated a close link between selected health risk behaviours and individual socioeconomic status in the Japanese population. A lower socioeconomic status measured according to income and occupation was generally associated with higher likelihood of health risk behaviours, such as current smoking and excessive alcohol consumption. Regional variance and the independent influence of regional indicators were marked in women, but small in men, and higher per capita income, reflecting an urban context, was related to accumulation of risk behaviours in women.

\section{Competing interests}

The author(s) declare that they have no competing interests.

\section{Authors' contributions}

YF designed the study, analyzed the data, and drafted the article. KN helped to interpret the results and edited the draft. TT supervised the data analysis and writing article.

\section{Acknowledgements}

This study was supported by Grant-in-Aid for Scientific Research (C) by the Japan Society for the Promotion of Science (Grant No. 14570326 and 16590497).

\section{References}

I. Acheson D: Independent inquiry into inequalities in health. London: Stationary Office; 2000.

2. Marmot $M$ : Inequalities in health. N Engl J Med 200I, 345: $134-136$.

3. Graham H: Understanding health inequalities. Buckingham: Open University Press; 2000.

4. Townsend P, Davidson N, Whitehead M: Inequalities in health: the Black Report and the health divide. London: Penguin Books; 1992.

5. Evans RG, Barer ML, Marmor TR: Why are some people healthy and others not? New York: Aldine de Gruyter; 1994.

6. Marmot M, Wilkinson RG: Social determinants of health. New York: Oxford University Press; 1999.

7. Shohaimi S, Luben R, Wareham N, Day N, Bingham S, Welch A, Oakes S, Khaw K: Residential area deprivation predicts smoking habit independently of individual education level and occupational social class. A cross sectional study in the Norfolk cohort of the European Investigation into Cancer (EPICNorfolk). J Epidemiol Community Health 2003, 57:270-276.

8. Turrell G, Blakely T, Patterson C, Oldenburg B: A multilevel analysis of socioeconomic (small area) differences in household food purchasing behaviour. J Epidemiol Community Health 2004, 58:208-2I5.

9. Parks SE, Housemann RA, Brownson RC: Differential correlates of physical activities in urban and rural adults of various socioeconomic backgrounds in the United States. J Epidemiol Community Health 2003, 57:29-35.

10. Galobardes B, Morabia A, Bernstein MS: Diet and socioeconomic position: does the use of different indicators matter? Int J Epidemiol 200I, 30:334-340.

II. Stahl T, Rutten D, Nutbeam D, Bauman A, Kannas L, Abel T, Luschen G, Rodriquez DJA, Vinck J, van der Zee J: The importance of the social environment for physically active lifestyle - results from an international study. Soc Sci Med 200I, 52: I- 10.

12. Duncan C, Jones K, Moon G: Do places matter? A multi-level analysis of regional variations in health-related behaviour in Britain. Soc Sci Med 1993, 37:725-733. 
13. Reijneveld SA: The impact of individual and area characteristics on urban socioeconomic differences in health and smoking. Int J Epidemiol 1998, 27:33-40.

14. O'Campo P: Advancing theory and methods for multilevel models of residential neighborhoods and health. Am J Epidemiol 2003, 157:9-13.

15. Krieger N: Theories for social epidemiology in the 2 I st century: an ecosocial perspective. Int J Epidemiol 200I, 30:668-677.

16. Diez Roux AV: Place, people, and health. Am J Epidemiol 2002 I55:516-5I9.

17. Diez Roux AV, Merkin SS, Arnett D, Chambless C, Massing M, Nieto J, Sorlie P, Szklo M, Tyroler HA, Watson R: Neighborhood of residence and incidence of coronary heart disease. $N$ Engl J Med 200I, 345:99-106.

18. Malmstrom M, Johansson SE, Sundquist J: A hierarchical analysis of long-term illness and mortality in socially deprived areas. Soc Sci Med 200I, 53:265-275.

19. Subramanian SV, Kawachi I, Kennedy BP: Does the state you live in make a difference? Multilevel analysis of self-rated health in the US. Soc Sci Med 2001, 53:9-19.

20. Sundquist K, Winkleby $M$, Ahlen H, Johansson S: Neighborhood socioeconomic environment and incidence of coronary heart disease: a follow-up study of 25,319 women and men in Sweden. Am J Epidemiol 2004, I 59:655-662.

21. Pickett KE, Pearl M: Multilevel analysis of neighbourhood socioeconomic context and health outcomes: a critical review. Epidemiol Community Health 2001, 55: III-I22.

22. Diez Roux AV, Merkin SS, Hannan P, Jacobs DR, Kiefe Cl: Area characteristics, individual-level socioeconomic indicators, and smoking in young adults. The coronary artery disease risk development in young adults study. Am J Epidemiol 2003, 157:315-326.

23. Sundquist J, Malmstrom M, Johansson SE: Cardiovascular risk factors and the neighbourhood environment: a multileve analysis. Int J Epidemiol 1999, 28:84I-845.

24. World Health Organization (WHO): World Health Report 2003. Geneva: WHO; 2003.

25. Marmot MG, Davey Smith G: Why are the Japanese living longer? BM] 1989, 299:|547-5|.

26. Wilkinson R: National mortality rates: the impact of inequity. Am J Public Health 1992, 82: I082-1083.

27. Saeki N, Hirako T, Sakata F, Ishikawa M, Nakata T: Vital statistics by occupation and industry. Koseino Shihyo 2000, 47(I): I0-16.

28. Fukuda Y, Nakamura K, Takano T: Municipal socioeconomic status and mortality in Japan: sex and age differences, and trends in 1973-1998. Soc Sci Med 2004, 59:2435-2445.

29. Anzai Y, Ohkubo T, Nishino Y, Tsuji I, Hisamichi S: Relationship between health practices and education level in the rural Japanese population. J Epidemiol 2000, 10:149-I56.

30. Nakamura Y, Sakata K, Kubo N, Akizawa Y, Nagai M, Yanagawa H: Smokng habits and socioeconomic factors in Japan. Epidemiol 1994, 4: I57-161.

31. Kanda A, Ojima T, Miura Y, Oguri S, Okayama A, Matsumura R, Yanagawa $\mathrm{H}$ : Prefectural difference in drinking, smoking, physical exercise, and obesity, and its trend. Koseino Shihyo 2002, 49(I5):7-I5.

32. Ministry of Health Labour and Welfare: 200 I Comprehensive Survey ofthe Living Conditions of People on Health and Welfare. Tokyo: Health and Welfare Statistics Association; 2003.

33. Mejer L, Siermann C: Income poverty in the European Union: children, gender and poverty gaps. Statistics in focus. Luxembourg: Eurostat; 2000.

34. Statistical Information Institute for Consulting and Analysis: Municipal data of social indicators. Tokyo: Statistical Information Institute for Consulting and Analysis; 2003.

35. Layland $\mathrm{AH}$, Goldstein $\mathrm{H}$ : Multilevel modelling of health statistics. Chichester: John Wiliy \& Sons; 200I.

36. Snijders TAB, Bosker RJ: Multilevel analysis: An introduction to basic and advanced multilevel modelling. London: Sage Publication; 1999.

37. Lindstrom M, Moghaddassi M, Merlo J: Social capital and leisure time physical activity: a population based multilevel analysis in Malmo, Sweden. J Epidemiol Community Health 2003, 57:23-28.

38. Rashash J, Browne W, Goldstein H, Yang M, Plewis I, Healy M, Woodhouse M, Draper D, Langford I, Lewis T: A user's guide to MLwiN.
London: Centre for Multilevel Modelling, Institute of Education, University of London; 2002.

39. Fukuda Y, Nakamura K, Takano T: Socioeconomic pattern of smoking in Japan: income inequality and gender and age differences. Ann Epidemiol 2005, I 5:365-72.

40. Ohida T, Kamal AMM, Takemura S, Sone T, Mochizuki Y, Kawaminami K: Relation between smoking prevalence and various social factors in Japan. Keio J Med 2001, 50:263-268.

4I. Ohida T, Sone T, Motizuki Y, Kawaguti T, Kido M, Harita A: Household size related to prevalence of smoking in women in Japan. J Epidemiol 2000, 1 0:305-309.

42. Takano T, Nakamura K, Watanabe M: Increased female drinking in accordance with post-industrial urbanization in Japan. Alcohol Alcohol 1996, 3 I:4 I-49.

43. Ministry of Health and Welfare: Survey of demands of health and welfare services. Tokyo: Health and Welfare Statistics Association; 2000.

44. Hamashima C, Yoshida $\mathrm{K}$ : What is important for the introduction of cancer screening in the workplace? Asian Pac J Cancer Prev 2003, 4:39-43.

45. Hirata M, Kumagai S, Tabuchi T, Tainaka H, Andoh K, Oda H: Actual conditions of occupational health activities in small-scale enterprises in Japan: system for occupational health, health management and demands by small-scale enterprises. Sangyo Eiseigaku Zasshi 1999, 41:190-201.

46. Duncan C, Jones K, Moon G: Smoking and deprivation: are there neighbourhood effects? Soc Sci Med 1999, 48:497-505.

47. Chaix B, Chauvin P: Tobacco and alcohol consumption, sedentary lifestyle and overweightness in France: a multilevel analysis of individual and area-level determinants. Eur J Epidemiol 2003, I 8:53।-538.

48. Chaix B, Guilbert P, Chauvin P: A multilevel analysis of tobacco use and tobacco consumption levels in France: are there any combination risk factors? Eur J Public Health 2004, 14: I86-190.

49. Institute for Posts and Telecommunications Policy: Indicators of regional affluence. Tokyo: Institute for Posts and Telecommunications Policy; 1997

50. Tachibanaki T: Japanese economy from the point of view of household economy. Tokyo: Iwanami; 2004.

5I. Cabinet Office: Report of regional economics 200I. Tokyo: National Printing Bureau; 200l.

52. Takano $\mathrm{T}, \mathrm{Nakamura} \mathrm{K}$ : The national financial adjustment policy and the equalization of health levels among prefectures. J Epidemiol Community Health 200I, 55:748-754.

53. Hotta $Y$, Araki S, Sato H, Yokoyama K: Social life factors for the mortality from motor vehicle accident. Jpn J Occup Med Traumatol 2000, 48:483-489.

54. Fukuda $\mathrm{Y}$, Nakamura $\mathrm{K}$, Takano $\mathrm{T}$ : Wide range of socioeconomic factors associated with mortality among cities in Japan. Health Promot Int 2004, 19:177-188.

55. Health and Welfare Statistics Association: Prefectural Life Table 2000. Tokyo: Health and Welfare Statistics Association; 2003.

56. Fukuda Y, Nakamura K, Takano T: Cause-specific mortality differences across socioeconomic position of municipalities in Japan, 1973-77 and 1993-98: increased importance of injury and suicide in inequality for ages under 75. Int J Epidemiol 2005, 34:100-109.

57. Gersten $O$, Wilmoth JR: The cancer transition in Japan since I95 I. Demographic Research 2002, 7:27I-306.

58. Kodama K, Sasaki H, Shimizu Y: Trend of coronary heart disease and its relationship to risk factors in a Japanese population: a 26-year follow-up, Hiroshima/Nagasaki Study. Jpn Circ J 1990 54:4|4-42|.

59. Sackett DL: Bias in analytic research. I Chron Dis 1979, 32:5I-63.

60. Delgado-Rodriguez M, Llorca J: Bias. J Epidemiol Community Health 2004, 58:635-64l.

6I. Health and Welfare Statistics Association: Kokumin Eiseino Doko. Tokyo: Health and Welfare Statistics Association; 2004.

62. Nakanishi N, Tatara K, Nakamura K, Suzuki K: Association of lifestyle with serum lipid levels: a study of middle-aged Japanese men. J Epidemiol 2000, 10:216-225

63. Morimoto K: Lifestyle and health - Health theory and demonstrable research. Tokyo: Igaku Shoin; 1991.

64. Schechtman KB, Barzilai B, Rost K, Fisher EB: Measuring physical activity with a single question. Am \& Public Health I99I, 8 I:771-773. 
65. Iwai $N$, Hisamichi $S$, Hayakawa $N$, Inaba $Y$, Nagaoka T, Sugimori $H$, Seki N, Skata K, Suzuki K, Tamakoshi A, Nakamura Y, Yamamoto A, Nishino Y, Ogihara A, Okamoto N, Suziki H, Morioka S, Ito Y, Wakai $\mathrm{K}$, Ojima $\mathrm{T}$, Tanaka $\mathrm{H}$, Nose $\mathrm{T}$, Ohono $\mathrm{Y}$ : Validity and reliability of single-item questions about physical activity. J Epidemiol 200I, II:21I-218.

66. Kunst $A E$, Mackenbach JP: Measuring socioeconomic inequalities in health. Copenhagen: WHO Regional Office for Europe; 1997.

67. Lynch J, Kaplan G: Socioeconomic position. In Social epidemiology Edited by: Berkman L, Kawachi I. New York: Oxford University Press; 2000:13-35.

68. Nishi N, Makino K, Fukuda H, Tatara K: Effects of socioeconomic indicators on coronary risk factors, self-related health and psychological well-being among urban Japanese civil servants. Soc Sci Med 2004, 58: I I 59-I I 70.

\section{Pre-publication history}

The pre-publication history for this paper can be accessed here:

http://www.biomedcentral.com/1471-2458/5/53/prepub

Publish with Biomed Central and every scientist can read your work free of charge

"BioMed Central will be the most significant development for disseminating the results of biomedical research in our lifetime. "

Sir Paul Nurse, Cancer Research UK

Your research papers will be:

- available free of charge to the entire biomedical community

- peer reviewed and published immediately upon acceptance

- cited in PubMed and archived on PubMed Central

- yours - you keep the copyright

Submit your manuscript here:

http://www.biomedcentral.com/info/publishing_adv.asp 